\title{
"O TOQUE PELA VIDA": THE IMPORTANCE OF THE PINK OCTOBER CAMPAIGNS FOR WOMEN HEALTH IN JATAÍ, GO
}

\author{
Sabrina R. J. Pimenta1,2, Thaynara B. C. Souza1,2, Izabella C. Amaral1,2, Thayanne S. Ramos ${ }^{1,2}$, Carlos A. L. Silva², \\ Carolina A. E. Terceiro², Bianca D. Vieira², Ana Paula S. Perez² \\ 1Department of Extension and Culture, Universidade Federal de Goías - Cidade (GO), Brazil. \\ ¿2Universidade Federal de Jataí - Jataí (GO), Brazil.
}

Objectives: The extension project "O Toque pela Vida" was created in 2016 by teachers, administrative technicians and Medicine students from the Federal University of Jataí (UFJ), in partnership with the Jataís Municipal Secretariat of Health (MSH). It aims to inform and guide the population regarding etiology, risk factors and early detection of Breast Cancer (BC), in addition to providing preventive examinations to women. Methodology: For the project execution, study groups were realized out monthly for the discussion of articles and clinical cases about BC. The information obtained during the groups discussions was used to design pamphlets, banners, posters, T-shirts and ribbons, symbols of the October Pink campaign. Extension activities and educational materials were disseminated on social networks, local radio and television programs. The activities were developed in the main Basic Health Units (BHUs) and in the Raízen Company of Jataí. Among these activities, on October 18, 2017, project students lecture on BC in the Raízen Company. On October 6, 2017, project participants went to BHUs to distribute information materials about BC and to disclose the D-Day Campaign. This campaign took place at BHU James Phillipe Minelli on October 28, and in the external area of the Unit, passwords were given to women for they could receive medical attention and care. Meanwhile, the project members measured the patients' pressure and glycemia. In addition, patients received guidance and clarification about BC, regarding risk factors, symptoms and early detection of cancer. The orientation activities were performed using anatomical breast molds, posters and ribbons distribution. Inside the unit, the patients updated the Unified Health System (UHS) card and filled in the necessary forms for medical care. The medical service were conducted by physicians, along with medical students. During the examinations, population screening for $\mathrm{BC}$ was verified, and women over 50 years old and/or presenting changes in clinical examination were scheduled for mammography. Results: During the activities held in the company, around 100 women employees, attended the educational lecture and, at the end, asked questions about BC. The project "O Toque pela Vida" was more widely accepted by the population, compared to the year 2016, which was the beginning of the project. In this year, the actions were focused only on the BC guidelines. However, in 2017, the partnership with MHS and the wide dissemination in the BHUs and media, allowed the project growth. Thereby, the D-Day brought around 200 women to the BHU James Phillipes Minelli. Of the 200 women, 152 were scheduled for mammograms performed by professionals from the Jataí's MHS, 09 were unilateral for diagnosis and 143 were bilateral for tracking the BC. Mammographies were scheduled between October 31 and December 1, 2017. Conclusion: The partnership established between the project "O Toque pela Vida" and the MHS shorted mammography waiting process in the Unified Health System (UHS). Thereby, the scheduling was quick and accessible to a great number of women, during the D-Day in October Pink Campaign. In addition to the activities developed during October, the study groups qualified the Medicine students and they were able to transmit the information to women population in a clear and correct way, taking into account that the project is composed by fresh and senior students. Therefore, the project proved itself of great relevance for the population, by providing more information and effecting the prevention and early diagnosis of breast cancer. 